"Modeling the function of advertising reviews from media ads on the YouTube channel"

Tetiana Bludova (D https://orcid.org/0000-0001-7011-5645

AUTHORS

R http://www.researcherid.com/rid/V-8495-2018

Andrii Chuzhykov

Kateryna Leshchenko

Tetiana Bludova, Andrii Chuzhykov and Kateryna Leshchenko (2019). Modeling

ARTICLE INFO the function of advertising reviews from media ads on the YouTube channel. Innovative Marketing , 15(3), 26-41. doi:10.21511/im.15(3).2019.03

DOI http://dx.doi.org/10.21511/im.15(3).2019.03

RELEASED ON Tuesday, 06 August 2019

RECEIVED ON Saturday, 15 June 2019

ACCEPTED ON Wednesday, 31 July 2019

(cc) $\mathbf{E}_{\mathrm{F}}$

LICENSE

This work is licensed under a Creative Commons Attribution 4.0 International License

\begin{tabular}{|c|c|}
\hline JOURNAL & "Innovative Marketing " \\
\hline
\end{tabular}

ISSN PRINT 1814-2427

ISSN ONLINE $1816-6326$

PUBLISHER

LLC "Consulting Publishing Company "Business Perspectives"

FOUNDER

LLC "Consulting Publishing Company "Business Perspectives"

NUMBER OF REFERENCES

25
NUMBER OF FIGURES

15
NUMBER OF TABLES

3

(C) The author(s) 2021. This publication is an open access article. 


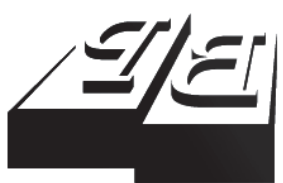

BUSINESS PERSPECTIVES

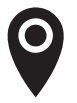

LLC "CPC "Business Perspectives" Hryhorii Skovoroda lane, 10, Sumy, 40022, Ukraine

www.businessperspectives.org

Received on: $15^{\text {th }}$ of June, 2019 Accepted on: $31^{\text {st }}$ of July, 2019

(C) Tetiana Bludova, Andrii Chuzhykov, Kateryna Leshchenko, 2019

Tetiana Bludova, Doctor of Economics, Professor, Marketing Faculty Advanced Mathematics Department, Kyiv National Economic University named after Vadym Hetman, Ukraine.

Andrii Chuzhykov, Candidate of Economic Sciences, Associate Professor, Faculty of International Economics and Management, Department of European Economy and Business, Kyiv National Economic University named after Vadym Hetman, Ukraine.

Kateryna Leshchenko, Candidate of Economic Sciences, Associate Professor, Faculty of International Economics and Management, Department of European Economy and Business, Kyiv National Economic University named after Vadym Hetman, Ukraine.

\section{(ㄷ)(i)}

This is an Open Access article, distributed under the terms of the Creative Commons Attribution 4.0 International license, which permits unrestricted re-use, distribution, and reproduction in any medium, provided the original work is properly cited.

Tetiana Bludova (Ukraine), Andrii Chuzhykov (Ukraine),

Kateryna Leshchenko (Ukraine)

\title{
MODELING THE FUNCTION OF ADVERTISING REVIEWS FROM MEDIA ADS ON THE YOUTUBE CHANNEL
}

\begin{abstract}
The use of display advertising enables companies to reach target audience and show them your ads on specific sites, which increases sales. In particular, YouTube video ads can reach a wide audience and attract many customers. One of the most important issues in the development of display advertising is the analysis and modeling of advertising reviews from media advertisements and practical tools with the aim of taking synergistic effects of advertising reviews. The purpose of the paper is to research the synergistic effects of advertising reviews in the system of successive advertising display. The study used a statistical analysis of empirical data, in particular statistics of annotations of video clips demonstration; viewing a video clip, and also approaching ad rotation time series using the Fourier series. The synergistic effects of advertising reviews in the system of successive advertising display are revealed. The approximation of time series of advertising reviews in the synergistic system of successive advertising display is presented. The analytical periodic function of advertising reviews, which takes into account manifestation of the short-term current effect of video advertising messages, is developed. The functions of advertising reviews in the Fourier series are presented, which allows to simulate video advertising messages as a reaction in the form of revision annotations in media advertising.
\end{abstract}

\section{Keywords}

\section{JEL Classification}

\section{INTRODUCTION}

Modern advertising business is a complex multi-structural process of influence on the consumer as it uses a large number of tools that until recently were considered inaccessible in this type of business. Numerous discussions are held in the field of economics regarding reference of advertising either to the mass media in which it is displayed, or, as other researchers do, advertising is positioned within the creative business (Howkins, 2007). The strategic positioning of the advertising sectors (Küng, 2009) and evaluation of impact of media management on the advertising market (Scannel, 2008) becomes of great importance in modern times. However, many studies focus on assessment of impact of the financial component on the media, in particular on $\mathrm{TV}$, receipt of orders from the advertisers (Hilmes, 2011) and commercialization of media products creating activities (Pierre Guillet de Monthoux, 2013). The psychologists apply some other approaches to advertising effectiveness, on the one hand, they criticize IP approaches (Giles, 2010), on the other hand, they support taking into account the effectiveness of this type of business (Giles, 2010). 
Taking into account the above discrepancies, Ukraine, which advertising space is used by a large number of companies, is an illustrative example, instead, since 2015, the Internet, advertising announcements on which are extremely important for both advertisers and network curators, has become the leading sector of the media and advertising market. It should be noted that on average in 2017 in Ukraine there were 22.1 million Internet users, of which 19.3 million users entered the network through desktop and laptop computers, 10.5 million - through smartphones/mobile phones, 2.6 million - through tablets. Among them, men accounted for $53 \%$ of all network users. In addition, it should be noted that according to the data provided by gemiusAudience in 2018, on average in Ukraine 16 million Internet users entered the network every week.

It should be noted that this kind of advertising is characterized by a tendency to expand and according to the data of the above-mentioned gemiusAudience, the mobile audience grew by 70\% during 2015-2016. In addition, it should be added that according to the data provided by Google Consumer Barometer, the average number of devices connected to the Internet increased 1.4 times per user in 2017 as compared to 2016. It is also quite revealing that the average number of people using two screens for access to the Internet (computer + smartphone or tablet) increased from $25 \%$ to $28 \%$, while those using three screens - from $7 \%$ to $10 \%$.The above trends quite vividly illustrate the tendency that most likely the promotional video will continue to evolve from the point of view of consumed content by users. According CISCO forecasts, $82 \%$ of all content consumed in the network will be the video content in 2020 . Therefore, it is easy to predict that to enhance the effective communication with video messages in Ukraine, the new Out-Stream formats will appear, which will permit to cover a much larger target audience, and their score will be less than In-Stream. It should also be noted that along with new technologies, the demand for training and advanced training will increase. The introduction of non-standard formats and software, based on international practice, is also expected. The convincing proof is that in 2017 the level of software procurement in the United States amounted to about half of all media advertising, while in Ukraine similar procurement did not exceed $35-38 \%$ in this year.

\section{METHODOLOGY}

The development of a methodology for modeling the function of advertising reviews from media ads in the conditions of digitalization is an urgent problem. In the processes of advertising messages, a special place is the study of reviews on them, based on the forming fundamentally new methodological approaches and substantiating practical measures for the scientific results implementation. New methodological approaches require the use of Fourier series to simulate the function of advertising responses, which takes into account the manifestations of the short-term current effect of video advertising hits.

\subsection{Literature review and theoretical basis}

In due time in the work of Larson (1987), it has been proven that most consumers have a certain resource of patience in waiting for longer queues. The duration of the service often affects its value, which is treated positively. Similarly, one can consider the patience of the viewer who is waiting for video advertising completion. The logical continuation of the study of the above tendencies should be the work of Oktay et al. (2010), which presents numerous evidence that potential viewers are much more likely to refuse to launch a longer video than a short one. Annotations embedded in long videos, such as for watching a certain episode or movie on TV, end more often than the embedded annotations in short video formats, such as a video clip or news feed.

It should be noted that some authors, in particular Eelen and Seiler (2015) who thoroughly researched creative media advertising, came to the conclusion that it creates the strongest brand associations. The researchers examined the theoretical mechanisms explaining how creative media affect consumers. Therefore, all empirical results regarding the creative media effects of advertising were analyzed. The researches of Van Reijmersdal, Rozendaal, and Buijzen (2012) convincingly 


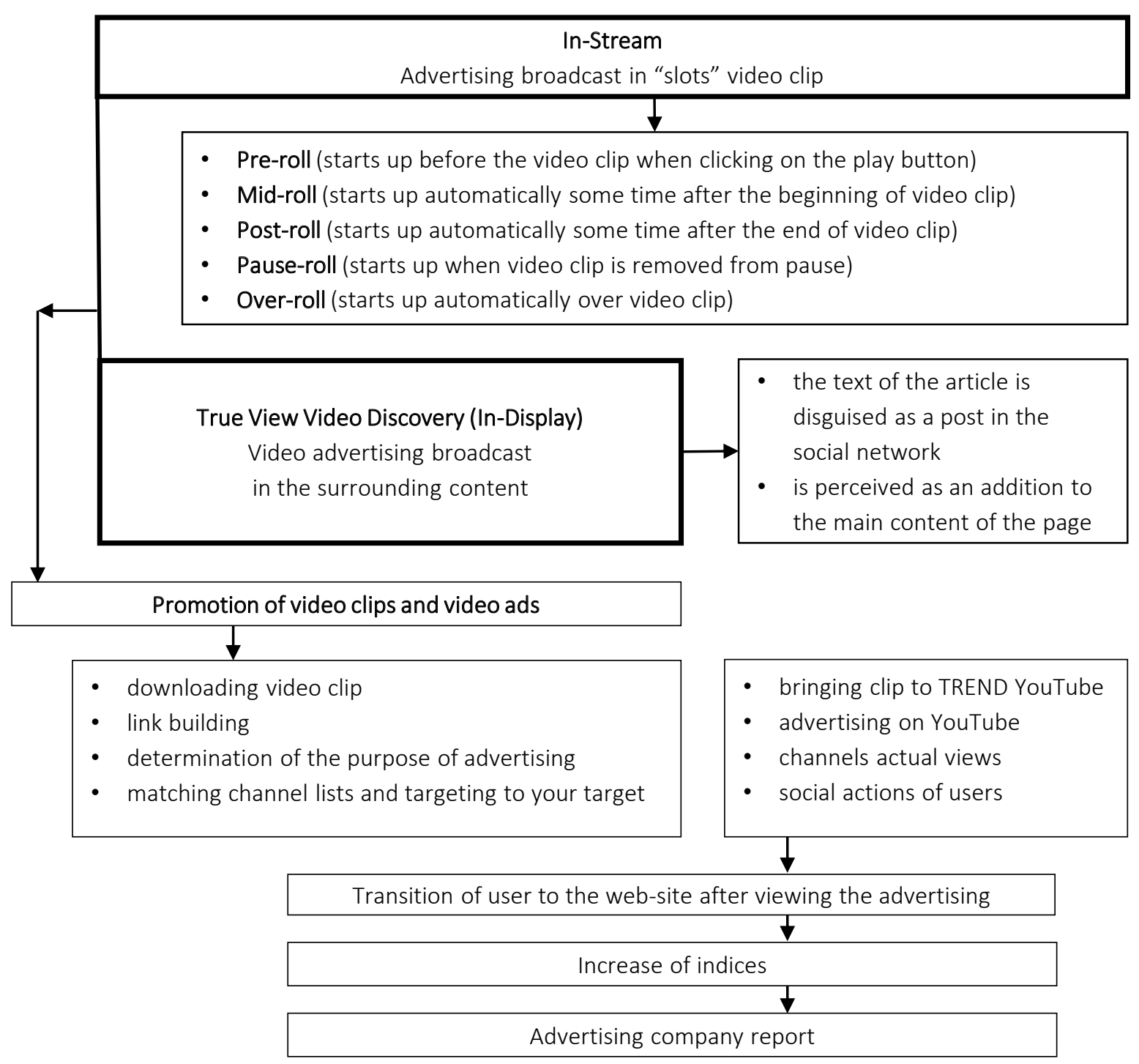

Figure 1. Structural chart of the production process from launching the video advertising-to-advertising company report

proved that, despite all activation measures, brand memory may remain low depending on application of this technique if the nature of connection between the medium and the message mobilizes the intellectual resources to support brand elements in advertising. Figure 1 shows the structural scheme of the production process from the launch of video advertising and to the report on the advertising company.

As we can see on Figure 1, there are two types of advertising on YouTube in TrueView format: In-Stream and TrueView Video Discovery (InDisplay). The characteristic feature of In-Stream format is that on mobile devices, the mobile ap- plication is also promoted along with video advertising, and even if the user skips certain video messages, the icon with the application remains throughout the main video. Thus, this application can be freely installed on any mobile device.

The important feature of TrueView Video Discovery (In-Display) format is that its advertising is displayed to the users, who are just beginning to search for video on YouTube, or in the list of search results, recommended videos, or in the list of other suggestions. The advertising has a text and a video icon. The size of such videos varies by location. Payment for video viewing is only charged if the user clicked on the video icon 


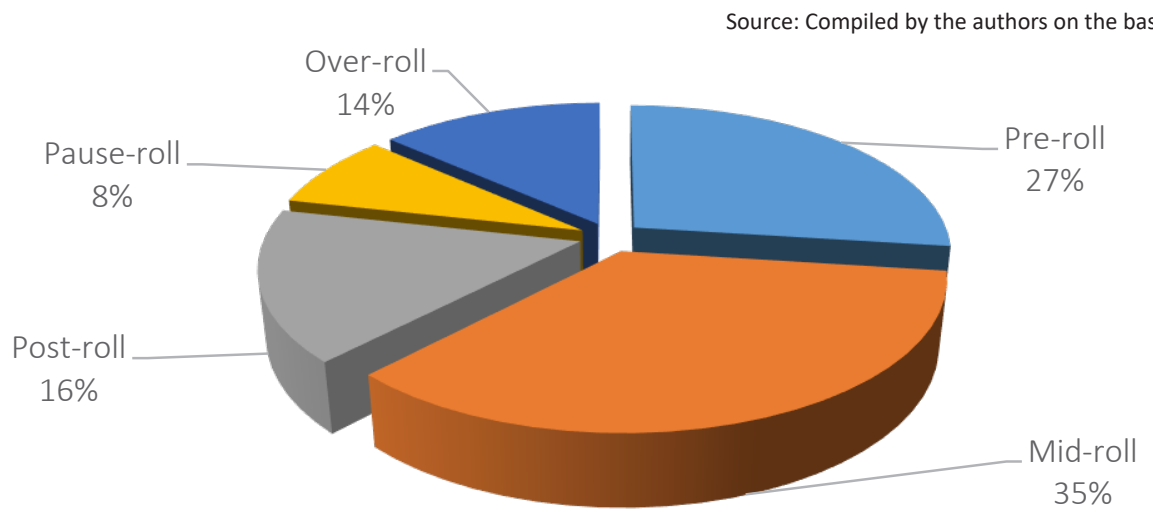

Figure 2. Level of annotations completion for all types of video advertising launch

and viewed its first frame. Note that there are several places to host a video: in YouTube search results; in the list of similar YouTube videos; on the YouTube homepage; as an overlay on the YouTube watch page.

According to the scheme on Figure 1, the targeting of video advertising customization, as substantiated by Eelen and Seiler (2015) includes the following elements: keywords, topics/categories, interest audiences, willing buyer audiences, interest specific audiences, demography, geography, specific video clips, specific YouTube channels, customary remarketing lists, video remarketing lists, web sites in the network, negative targeting (exceptions are meant).In the work of such scholars as Shunmuga and Sitaraman (2012), the authors proposed an innovative Quasi Experimental Design (QED) instrument for use in studies of network statistical measurements. Figure 2 shows the level of completion of annotations. Most often mid-roll average announcements end when video is viewed and the user wants to see more.

As part of the statistical analysis of the advertising company, it was ascertained that there is connection of AdWords account with the YouTube channel: access to YouTube Analytics, i.e. to the statistics regarding interaction of the user with the video clip on the following points: how users view videos, which topics are most interesting for consumers, what kind of devices the consumers use, how much time they spend on the Internet, for what purpose they watch video in Ukraine (to find information, for hobbies, to learn, for fun, for recreation).
Table 1 shows types, possibilities, effects and fields of use of video advertising as distribution for video companies.

Table 1. Video advertising effects

Source: Compiled by the authors on the basis of Hutter (2015).

\begin{tabular}{|c|c|c|}
\hline Types & Possibilities & Fields of use \\
\hline $\begin{array}{l}\text { Extensions for } \\
\text { video companies } \\
\text { and video } \\
\text { advertising }\end{array}$ & $\begin{array}{l}\text { Add interactive } \\
\text { elements to video clip }\end{array}$ & $\begin{array}{l}\text { The viewers will } \\
\text { not only watch the } \\
\text { video clip, but also } \\
\text { interact with the } \\
\text { advertiser's brand } \\
\text { and channel }\end{array}$ \\
\hline Annotations & $\begin{array}{l}\text { Created in the YouTube } \\
\text { interface. You can add } \\
\text { them only after linking } \\
\text { the site to YouTube } \\
\text { account }\end{array}$ & $\begin{array}{l}\text { Used if you want } \\
\text { to tell the viewers } \\
\text { about your website } \\
\text { directly in the } \\
\text { video clip }\end{array}$ \\
\hline $\begin{array}{l}\text { Prompting } \\
\text { messages }\end{array}$ & $\begin{array}{l}\text { Created in the YouTube } \\
\text { interface. Other video } \\
\text { clips or playlists are } \\
\text { promoted to support } \\
\text { interest in the channel }\end{array}$ & $\begin{array}{l}\text { Bring context to } \\
\text { the attention of the } \\
\text { viewers and add } \\
\text { information value } \\
\text { to the video clips } \\
\text { and promote their } \\
\text { goods and services } \\
\text { directly in the } \\
\text { video }\end{array}$ \\
\hline $\begin{array}{l}\text { Call-to-action } \\
\text { overlays }\end{array}$ & $\begin{array}{l}\text { Only one overlay can } \\
\text { be placed in each } \\
\text { video }\end{array}$ & $\begin{array}{l}\text { Urge users to link } \\
\text { to your web-site }\end{array}$ \\
\hline $\begin{array}{l}\text { Accompanying } \\
\text { banner }\end{array}$ & $\begin{array}{l}\text { Guarantees permanent } \\
\text { brand presence even } \\
\text { after the video is } \\
\text { over. Added when } \\
\text { creating In-Stream } \\
\text { video advertising. The } \\
\text { system automatically } \\
\text { picks up a picture for a } \\
\text { banner, there is also an } \\
\text { opportunity to upload } \\
\text { your own }\end{array}$ & $\begin{array}{l}\text { The user can click } \\
\text { on it at any time }\end{array}$ \\
\hline $\begin{array}{l}\text { Metadata for } \\
\text { video }\end{array}$ & $\begin{array}{l}\text { Description to the } \\
\text { video }\end{array}$ & $\begin{array}{l}\text { Description of the } \\
\text { video clip gives the } \\
\text { viewer a general } \\
\text { idea of its content }\end{array}$ \\
\hline
\end{tabular}


Table 2. Benefits of video advertising on the YouTube channel

Source: Compiled by the authors on the basis of Dilley et al. (2010), Nygren et al. (2015).

\begin{tabular}{|c|c|}
\hline Possibilities & Effects and uses \\
\hline Affordable price & The cost of video advertising on the Internet is much less than that of television advertising \\
\hline Brand recognition & $\begin{array}{l}\text { Video advertising promotes enhancing the image. Even without promotion the video clip } \\
\text { "works" itself on the web-site of the company, various types of video files placement in } \\
\text { social networks }\end{array}$ \\
\hline Advertising of special goods and services & $\begin{array}{l}\text { Video advertising is irreplaceable where it is impossible or not enough to photograph and } \\
\text { describe any product and service }\end{array}$ \\
\hline Easy perception of advertising & $\begin{array}{l}\text { In a matter of minutes, the user can familiarize himself with the brand and the advertiser's } \\
\text { goods }\end{array}$ \\
\hline Easy placement & It is enough to upload video to YouTube \\
\hline Broad reach of the target audience & Advertising can affect people with specific interests who are interested in specific topics \\
\hline Quick analysis of video advertising & AdWords and YouTube analytics \\
\hline Unity of advertising platforms & $\begin{array}{l}\text { Video clips with a link to the web-site can be placed on video hosting, blogs and social } \\
\text { networks, it is easy to send video to customers by e-mail }\end{array}$ \\
\hline
\end{tabular}

Table 2 provides possibilities, effects and uses as the main benefits of placing video advertising on the YouTube channel.

Thus, taking into account the benefits of video advertising on YouTube (Table 2) and using several additional functions, you can attract significantly more viewers to video advertising, and ensure a significant increase in the number of interactions and brand recognition.

As little research is available on consumer response to advertising as an interactive technology innovation, the study (Lin \& Kim, 2016) assesses the effects of user perceptions of privacy risk, intrusiveness concerns and utilities of sponsored advertising on consumer attitudes and purchase intent. The hypothesized relations between perceived usefulness, ease of use, attitudes and purchase intentions were also validated.

At the same time, there are a number of issues that need to be addressed, including determining how optimized video ads are when modeling the ad process, as well as studying the effects of a synergistic ad serving system.

Thus, the question arises of modeling the process of advertising appeals. This should help to increase the effectiveness of advertising reviews and increase profits, due to the fact that information transmitted to the consumer will incline him to purchase, which is an urgent problem.

In innovative marketing, Fourier series is mainly used in demand analysis, as in the article of
Fumi, Pepe, Scarabotti, and Schiraldi (2013). There is also research on using Fourier analysis to determine market cycles and for stock price forecasting that is presented in scientific work of Stádník, Raudeliuniene, and Davidavičienè (2016).

In order to simulate the function of advertising responses from video promotional hits, we need to consider a statistical analysis of advertising responses in some examples.

\subsection{Statistical analysis of advertising feedback}

Let us analyze the statistics of advertising feedback received from Greenlight-studio regarding the annotations used in the promotional video. The data sets we use for our analysis of media analytics were collected from viewing of real users, who watched a specific video, using different network connection devices on the Internet. Table 3 presents the main statistics for the period of 21 days of effect of advertising message in the video clip. Figure 4 shows the annotation statistics (clicks, number, closing of annotations) of video demonstration for 21 days of browsing for various network connection devices over the Internet - mobile phone, tablet PC, computer, and TV. It should be noted that the most closing of annotations was through mobile phones. It is stated in the work of Liu et al. (2012) that a significant number of viewers refuses to review annotations immediately after the start of video advertising, and they do it at a rather high speed. 
Table 3. Statistics of annotations in video clip screening for the period of 21 days of browsing

\begin{tabular}{|c|c|c|c|c|c|c|c|}
\hline Date & $\begin{array}{c}\text { Clicks on } \\
\text { annotations }\end{array}$ & $\begin{array}{l}\text { Number of } \\
\text { clicks per } \\
\text { annotation }\end{array}$ & $\begin{array}{c}\text { Closing of } \\
\text { annotations }\end{array}$ & $\begin{array}{c}\text { Closed } \\
\text { annotations }\end{array}$ & $\begin{array}{c}\text { Screening of } \\
\text { annotation } \\
\text { with links }\end{array}$ & $\begin{array}{c}\text { Screening of } \\
\text { annotations } \\
\text { with "Close" } \\
\text { button }\end{array}$ & $\begin{array}{l}\text { Screening of } \\
\text { annotations }\end{array}$ \\
\hline December 13, 2017 & 0 & 0 & 0 & & 7 & 0 & 7 \\
\hline December 14,2017 & 0 & 0 & 0 & 0 & 4 & 1 & 4 \\
\hline December 15, 2017 & 0 & 0 & 0 & & 1 & 0 & 1 \\
\hline December 16, 2017 & 0 & 0 & 0 & 0 & 4 & 2 & 4 \\
\hline December 17, 2017 & 1 & 25 & 0 & 0 & 4 & 2 & 4 \\
\hline December 18, 2017 & 41 & 1,54 & 712 & 26,85 & 2660 & 2652 & 2660 \\
\hline December 19, 2017 & 1 & 1,43 & 18 & 26,09 & 70 & 69 & 70 \\
\hline December 20, 2017 & 0 & 0 & 0 & 0 & 10 & 10 & 10 \\
\hline December 21, 2017 & 2 & 0,75 & 58 & 22,05 & 267 & 263 & 267 \\
\hline December 22, 2017 & 46 & 2,27 & 432 & 21,46 & 2022 & 2013 & 2022 \\
\hline December 23, 2017 & 2 & 3,08 & 13 & 20 & 65 & 65 & 65 \\
\hline December 24, 2017 & 0 & 0 & 2 & 20 & 14 & 10 & 14 \\
\hline December 25, 2017 & 0 & 0 & 5 & 26,32 & 20 & 19 & 20 \\
\hline December 26, 2017 & 26 & 1,7 & 281 & 18,46 & 1529 & 1522 & 1529 \\
\hline December 27, 2017 & 0 & 0 & 8 & 19,05 & 43 & 42 & 43 \\
\hline December 28, 2017 & 0 & 0 & 0 & 0 & 2 & 2 & 2 \\
\hline December 29, 2017 & 0 & 0 & 0 & 0 & 4 & 2 & 4 \\
\hline December 30, 2017 & 25 & 2,18 & 207 & 18,06 & 1149 & 1146 & 1149 \\
\hline December 31, 2017 & 0 & 0 & 2 & 66,67 & 3 & 3 & 3 \\
\hline January 2, 2018 & 0 & 0 & 0 & 0 & 2 & 1 & 2 \\
\hline January 3, 2018 & 0 & 0 & 1 & 20 & 5 & 5 & 5 \\
\hline January 4, 2018 & 0 & 0 & 1 & 16,67 & 9 & 6 & 9 \\
\hline January 5, 2018 & 0 & 0 & 1 & 20 & 7 & 5 & 7 \\
\hline
\end{tabular}

View rate is an important metric to understand how well the ad is performing. A higher view rate means the ad is keeping customers engaged. About a third of viewers close annotations in the first quarter of video advertising, and only about two thirds of viewers relinquish their positions in the middle of video advertisings. Figure 4 shows the dynamics of annotations (clicks, number, closing of annotations, Figure 3 ) in the process of demonstration of video clip during the above time lag. Surely, in the process of analyzing the reactions of different groups of consumers to promotional videos, the gender and age characteristics of the audience and their level of perception are of paramount importance.

Our goal is to drive conversions, not just brand awareness, then you can reduce your targeting. This increases the chances that the ads are likely to be viewed by those who are most likely to attract and convert. You can target your audience on YouTube in many ways to narrow down the audience who sees these ads. What matters is gender and demographic groups. Figure 5 illustrates the gender peculiarities of watching a video clip for 21 days of observation for people aged 18-24 years. Figure 5 shows that the time of viewing of Internet information by men is almost 2 times more than that of women.

Figure 6 illustrates gender preferences of viewing video clips of a definite time lag by persons aged 25-32 over the analyzed period. Figure 6 shows that the time of watching a video clip by men of this age is almost 2.3 times longer.

It is stated in the work of Dobrian et al. (2011) that IAB (Interactive Advertising Bureau) identifies video advertising as a long form of video that is demonstrated for over 2 minutes, and as a short form, which demonstration does not exceed 2 minutes. Figure 7 shows the results of analyzing the length of viewing a long video clip during the 
Source: Compiled on the basis of www.greenlight-studio.com.ua

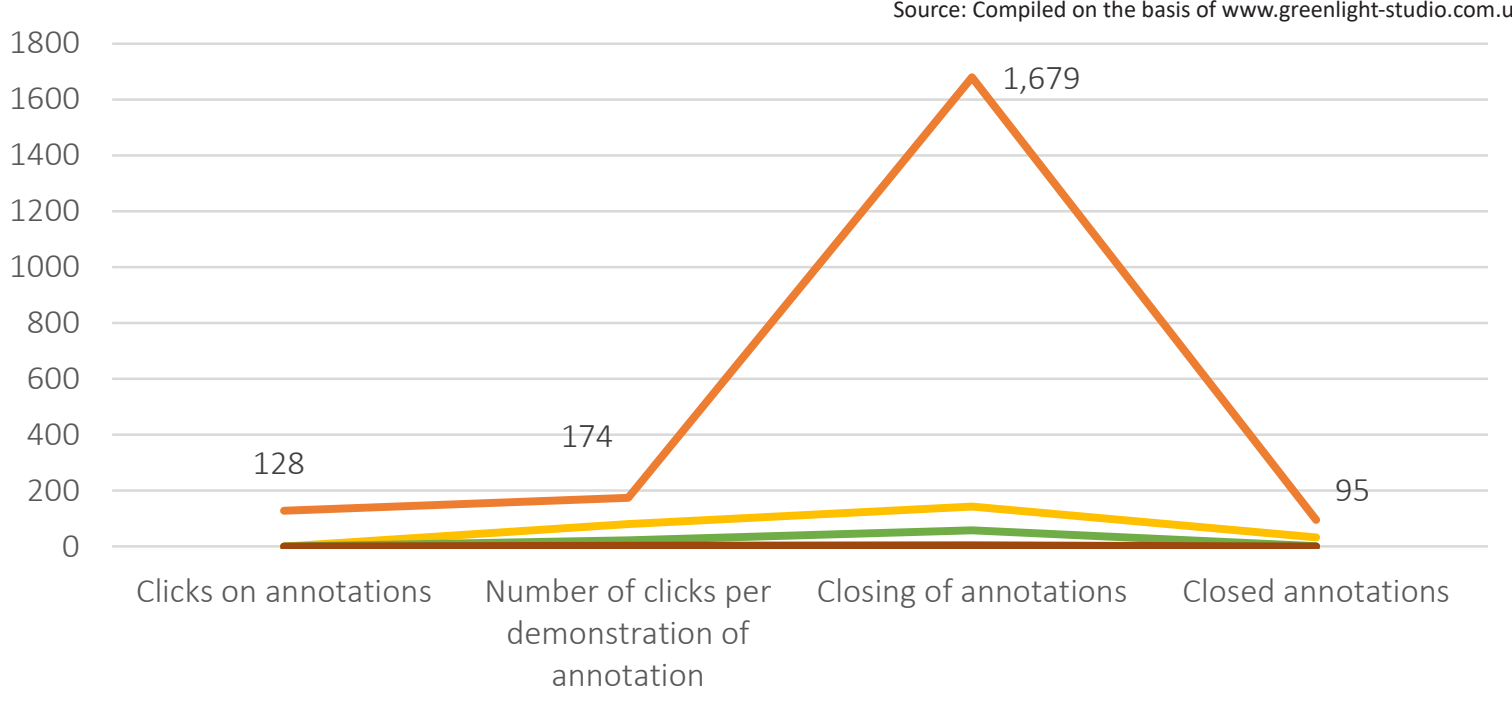

Mobile phone Tablet PC C Computer $\longrightarrow$ TV

Figure 3. Annotation statistics of video clip demonstration for 21 days of browsing for various network connection devices over the Internet

Source: Compiled on the basis of www.greenlight-studio.com.ua

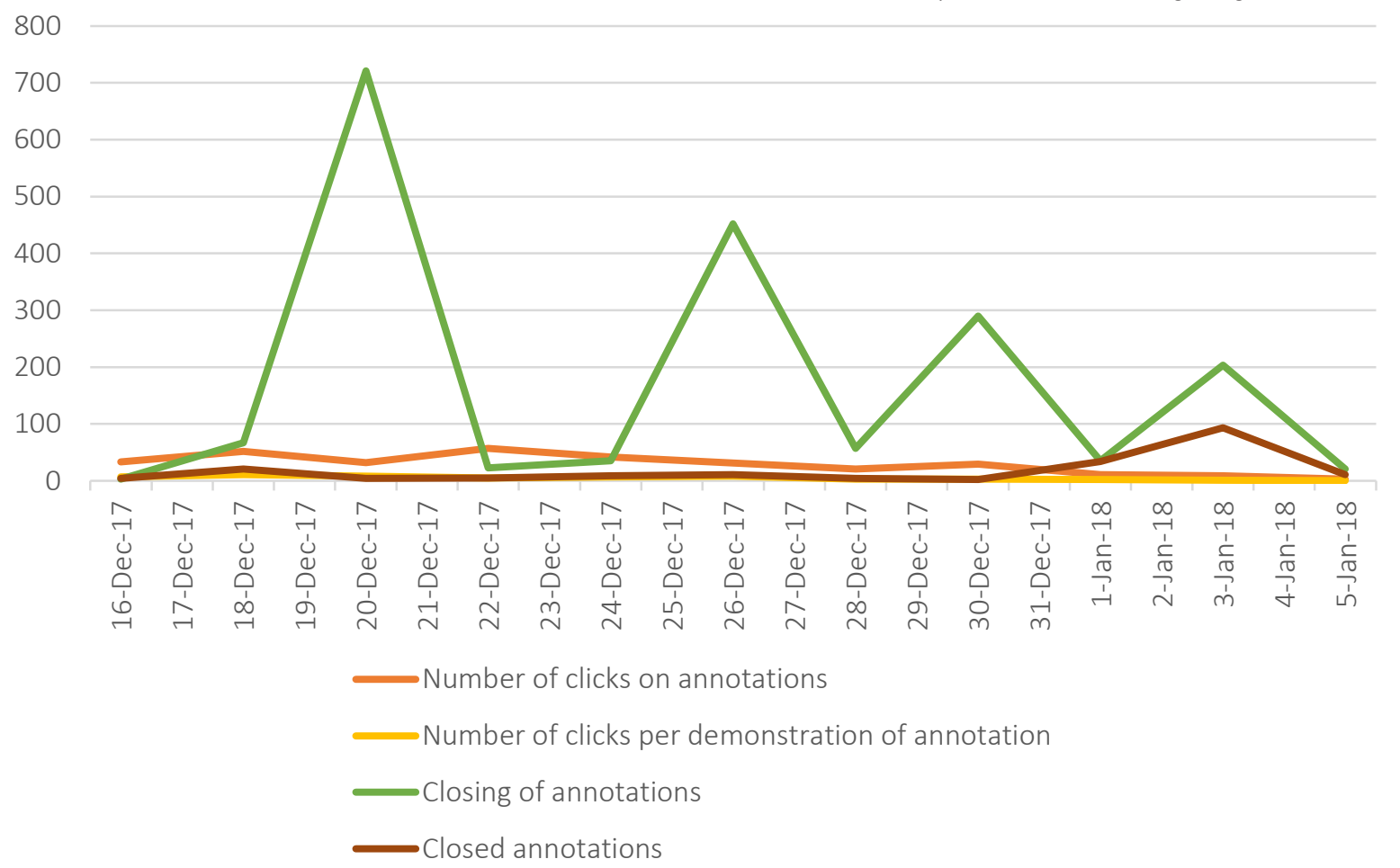

Figure 4. Dynamics of annotations in video clips demonstrations during the period of December 16, 2017 - January 5, 2018

observation period for mobile phones and tablet PCs with priority of mobile phones.

Figure 8 shows the analysis of length of viewing a video clip during 21 days of observation for computers and TV with priority of computers.
Figure 9 shows the analysis of duration of viewing advertising content of a video clip during 21 days of observation on YouTube. In our opinion, the analysis presented would seem incomplete if the research focused only on average data on YouTube as attractiveness for the user of its individual pag- 


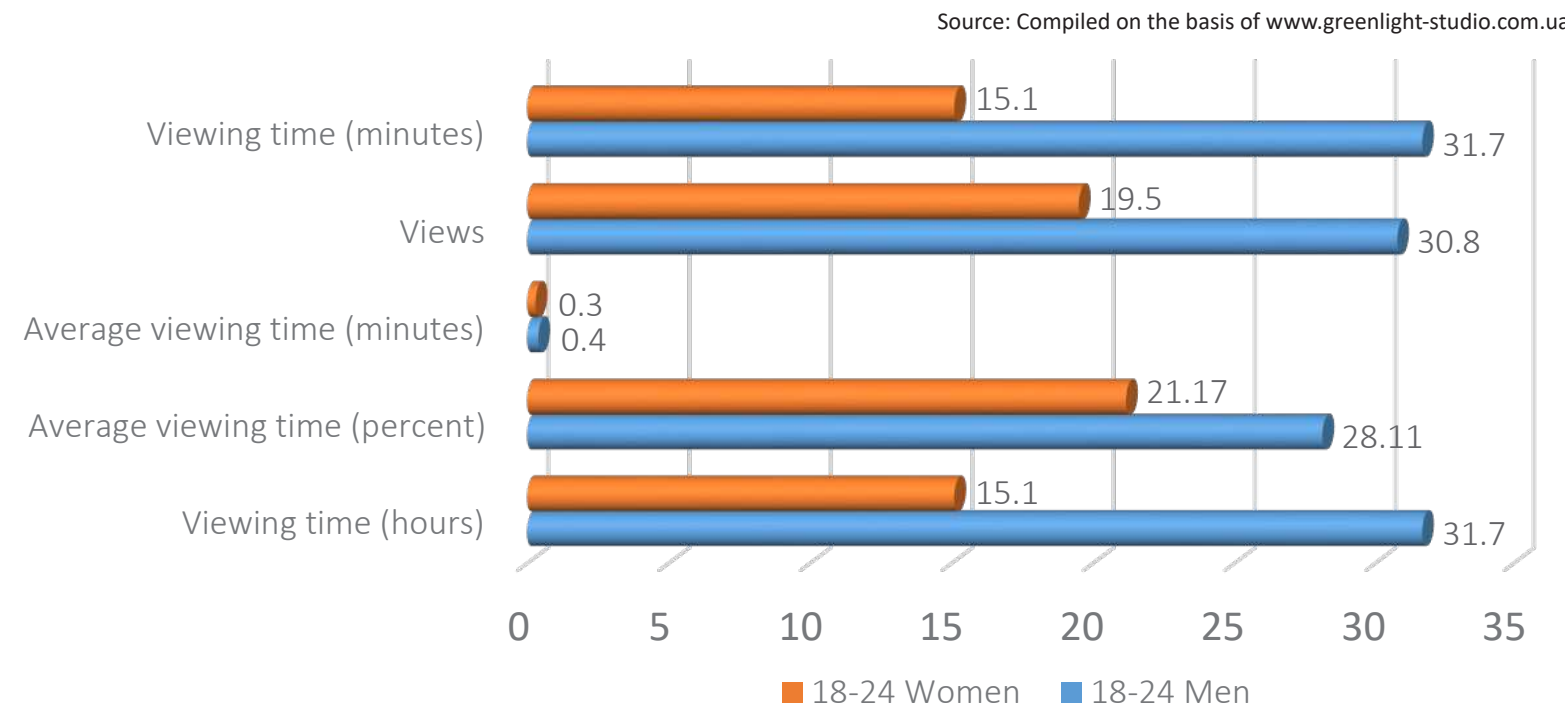

Figure 5. Gender peculiarities of viewing a video clip for 21 days for people aged 18-24 years

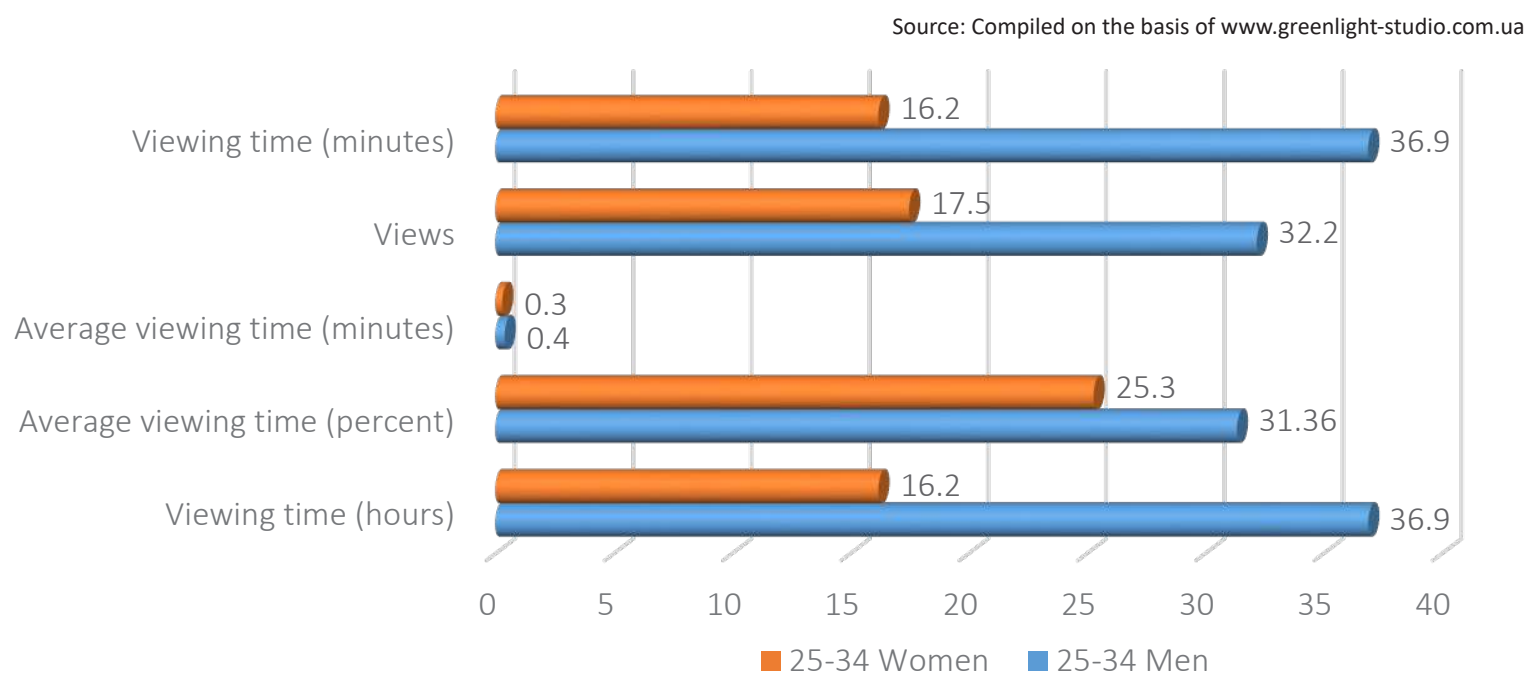

Figure 6. Gender preferences of viewing video clip during 21 days for observation by persons aged 25-34

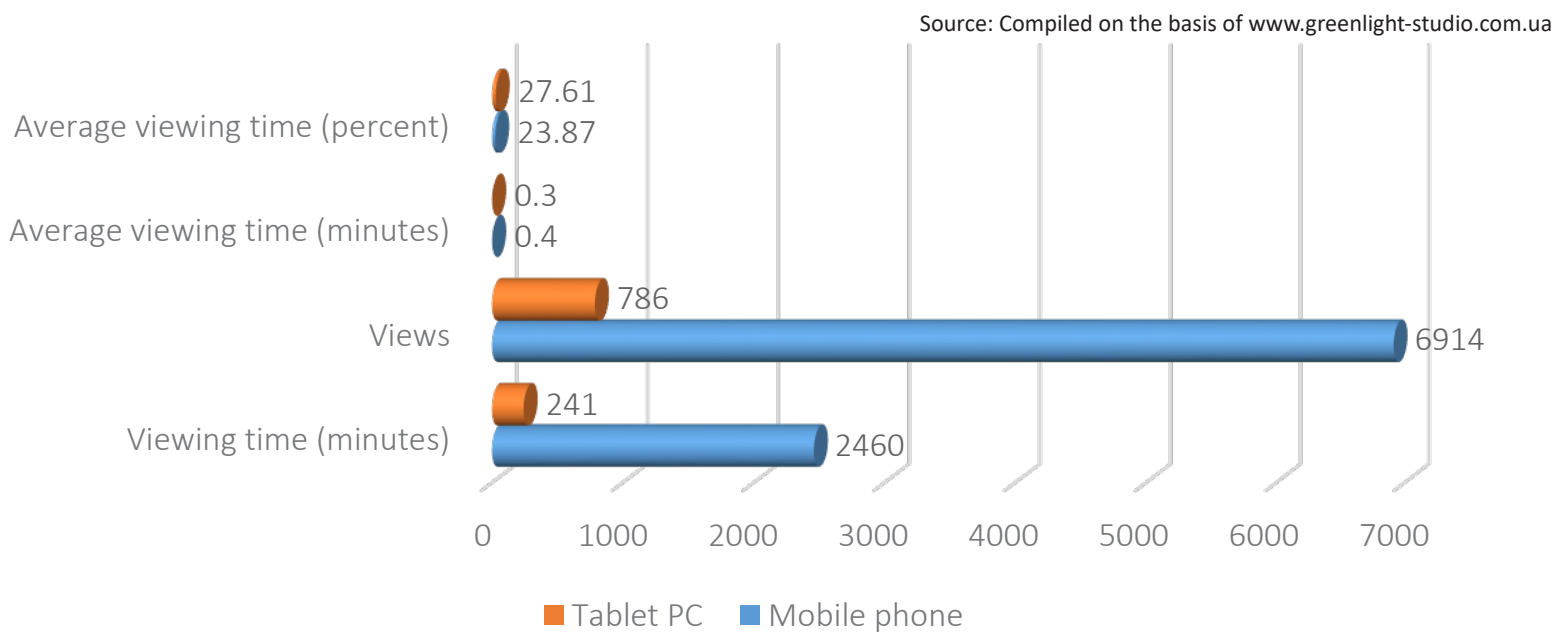

Figure 7. Analysis of length of viewing a video clip for 21 days for mobile phones and tablet PCs 


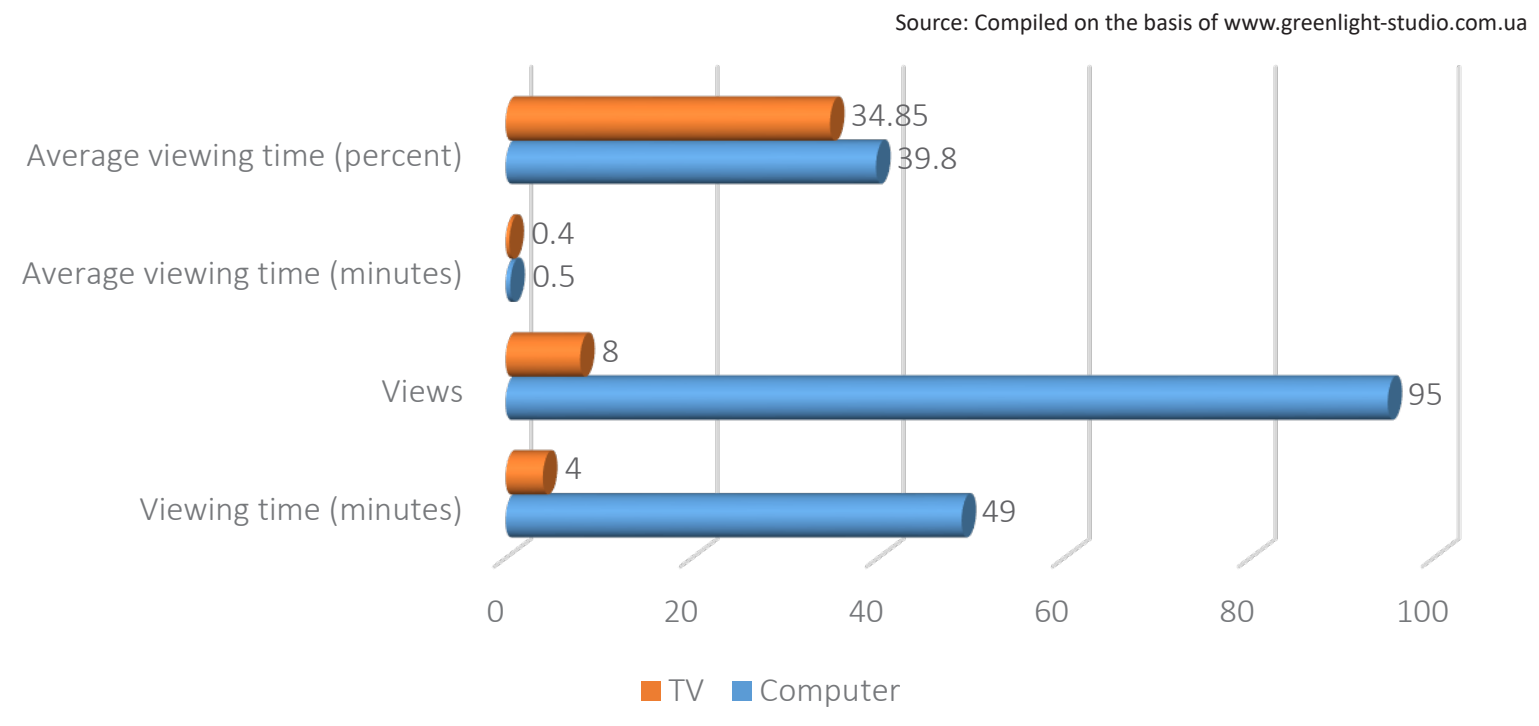

Figure 8. Analysis of length of viewing a video clip for 21 days of observation for computer and TV

Source: Compiled on the basis of www.greenlight-studio.com.ua

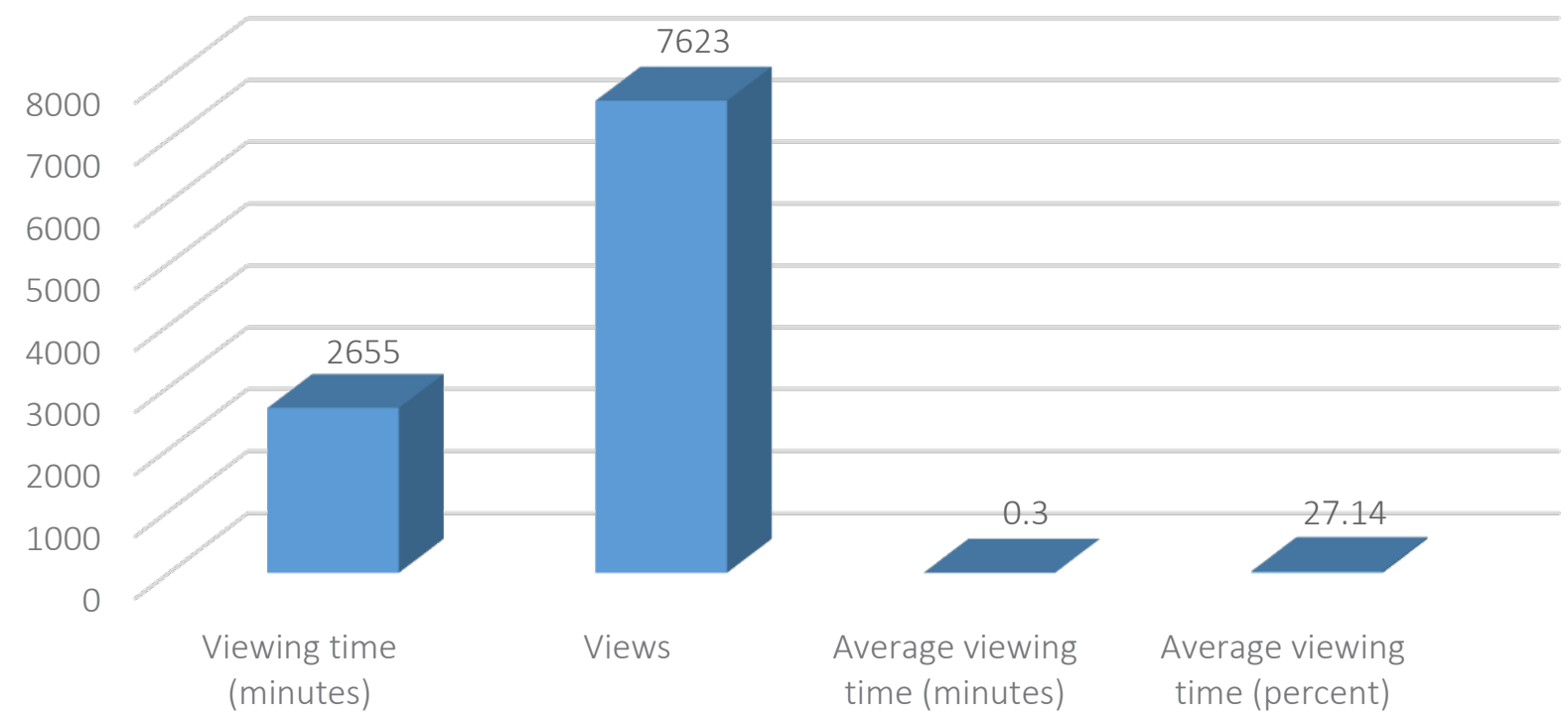

Advertising on YouTube

Figure 9. Analysis of duration of viewing advertising content of a video clip during 21 days of observation on YouTube

es and neglect of others may form a misconception about the demand for advertising content.

The alleged contradictions were quite easily overcame in Figure 10.

The above statistical analysis of advertising reviews is mandatory for statistical analysis of the effects of advertisements. These include the effects of advertising reviews in the In-Stream advertising system and in the TrueView Video Discovery (In-Display) advertising system.

However, there is a need to study the synergistic relationship between these two effects, which is discussed in the next subsection. 
Source: Compiled on the basis of www.greenlight-studio.com.ua

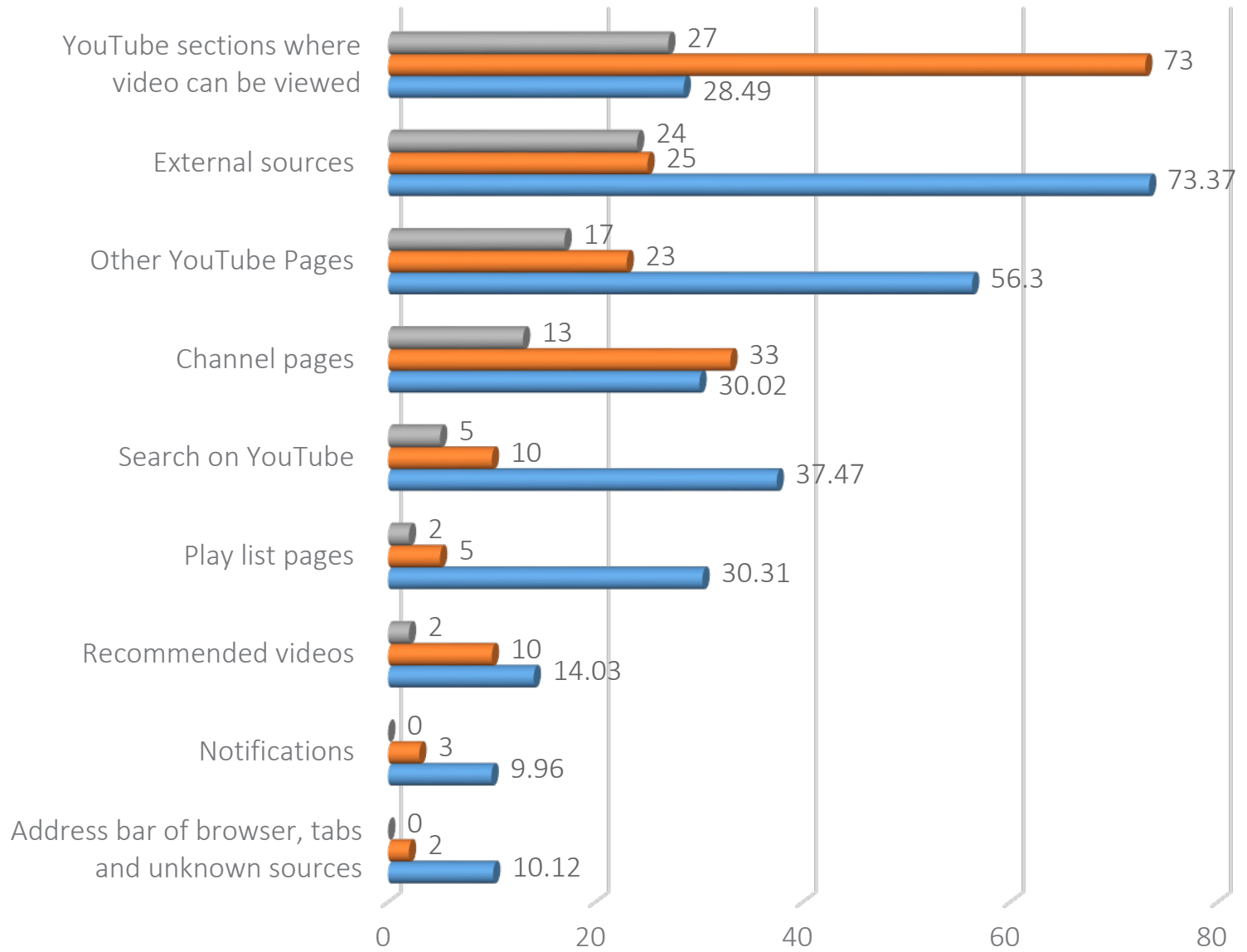

Figure 10. Analysis of video clip views during 21 days of observations on various YouTube pages

\subsection{Effects of advertising reviews}

Figure 11 schematically presents the short-term effects of advertising reviews (dashed lines) in the In-Stream advertising system. As we can see in Figure 12, advertising reviews ceased to arrive concurrently with completion of demonstration, end of the promotional video in In-Stream. Provided that the advertisement was not broadcast, the situation that advertising reviews were not received seems quite logical.

Figure 12 schematically shows the short-term effects of advertising reviews (dotted lines) in the TrueView Video Discovery (In-Display) advertising system.

As we can see at Figure 11, the above-mentioned advertising reviews end before demonstration of the promotional video in In-Display ends. It hap- pens during the week when the advertisement is not broadcast, and it is therefore easy to note that no advertising responses were received during this time period.

In our opinion, Figure 13 quite vividly shows the synergistic effects of advertising reviews (dashed lines) in a consistent advertisement broadcasting system: In-Stream and TrueView Video Discovery (In-Display).

Under these conditions, alignment of advertising reviews with those presented in Figure 11 is observed. In addition, extension of the effect of duration of advertising reviews, even after the end of In-Display video advertising, is noted. The consistent pattern (and most likely the additional effect) is due to the fact that when you enter InDisplay video advertising, advertising reviews have already gained the appropriate potential in 
Source: Compiled by the authors on the basis of research.

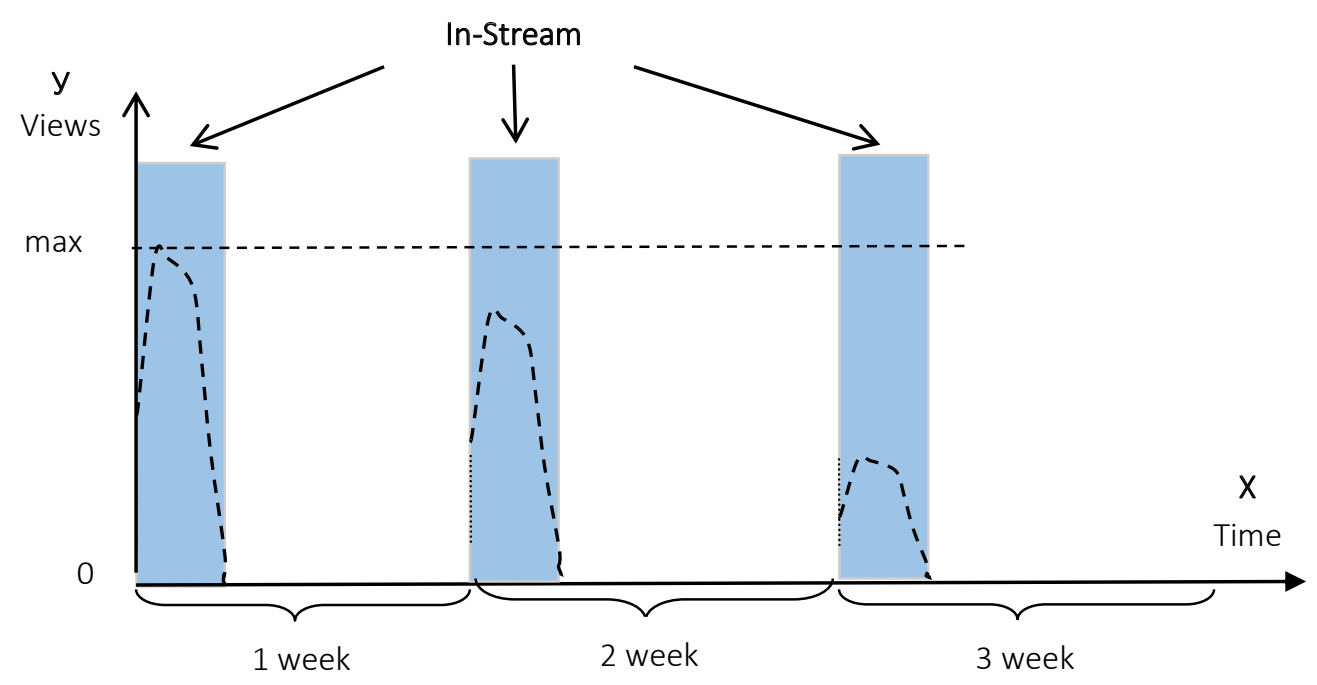

Figure 11. Effects of advertising reviews (dashed lines) in the In-Stream advertising system

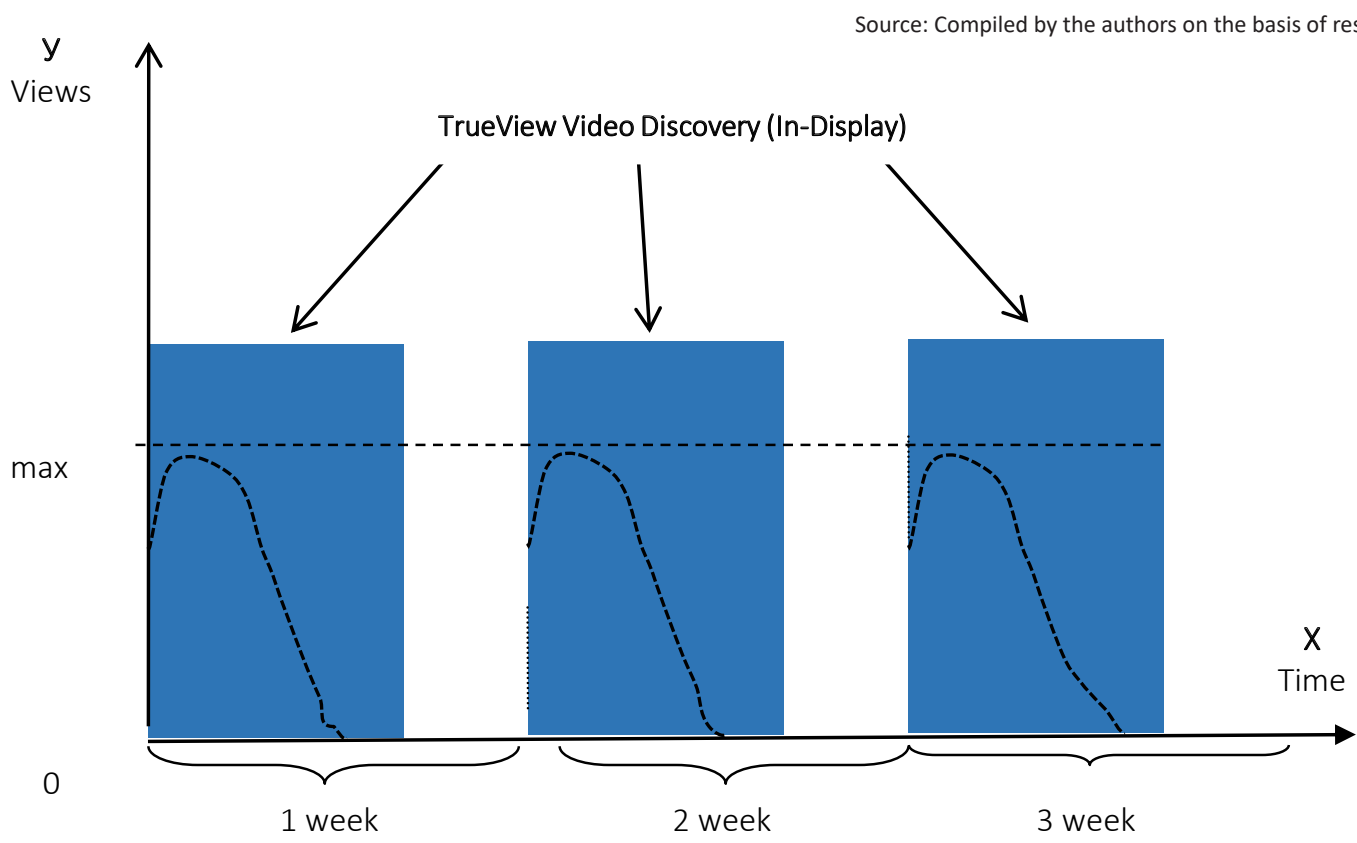

Figure 12. Effects of advertising reviews (dashed lines) in the TrueView Video Discovery (In-Display) advertising system

In-Stream video advertising. It permits to consist- ing broadcast system: In-Stream and TrueView ently display two different types of video advertis- Video Discovery (In-Display), gives the basis for ing on YouTube in TrueView format: In-Stream mathematical modeling of these effects using and TrueView Video Discovery (In-Display).

Fourier series.

A statistical analysis of the feedback on adver- In this article, we decided to use Fourier series for tising, as well as a study of the synergistic ef- modeling advertising responses, which is presentfects of advertising reviews in a serial advertis- ed in the next section. 


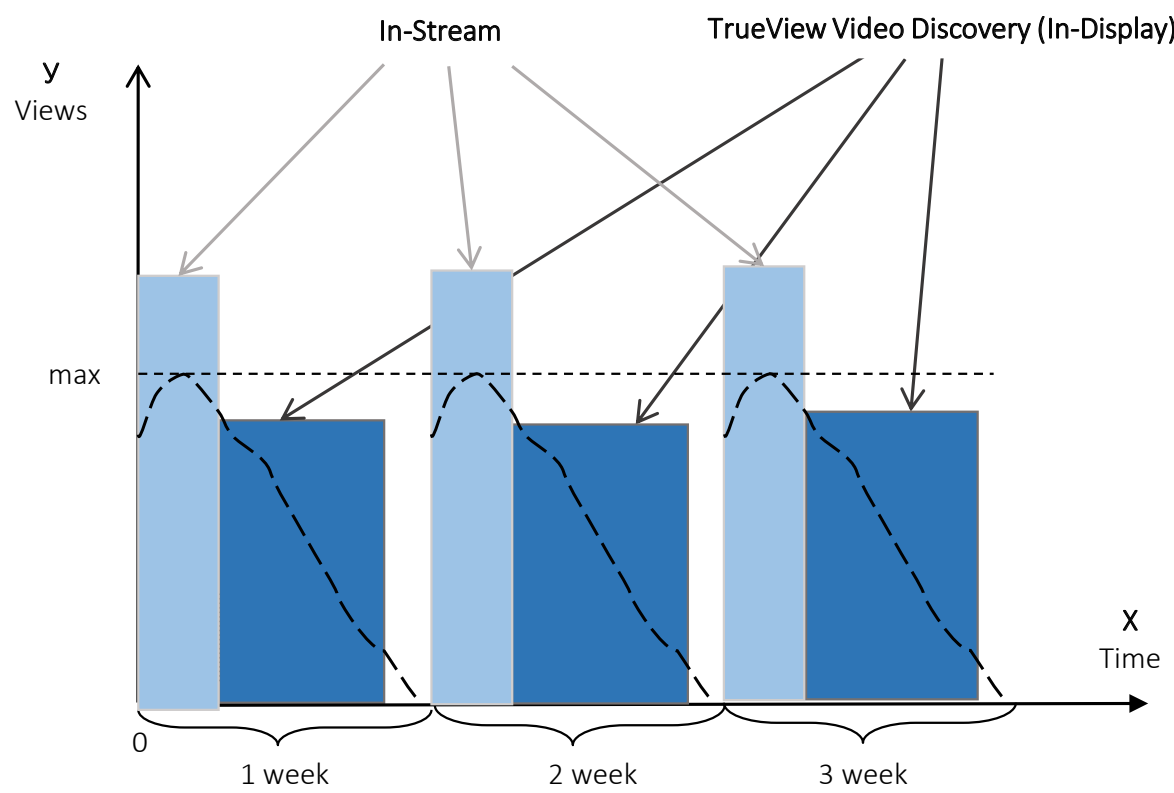

Figure 13. Synergistic effects of advertising reviews (dashed lines) in a consistent advertisement broadcasting system: In-Stream and TrueView Video Discovery (In-Display)

\section{RESULTS}

According to the statistics of advertising reviews posted by Greenlight-studio, approximation was constructed, according to the approach proposed by Wolfe and Hollander (1973) using the Moving Average Method, which made it possible to approximate the time series to exclude the influence of a random component (Figure 15). In Figure 15, the OX axis is time, and on the OY axis - views. Please see below the analytical periodic function of views - advertising reviews:

$$
y=\left\{\begin{array}{cc}
1.06^{1-(x+k)}, & k<x<k+1 \\
1.03, & x=k
\end{array} .\right.
$$

Note that 1.03 is the average value at the point of discontinuity of the function of the first kind. Let

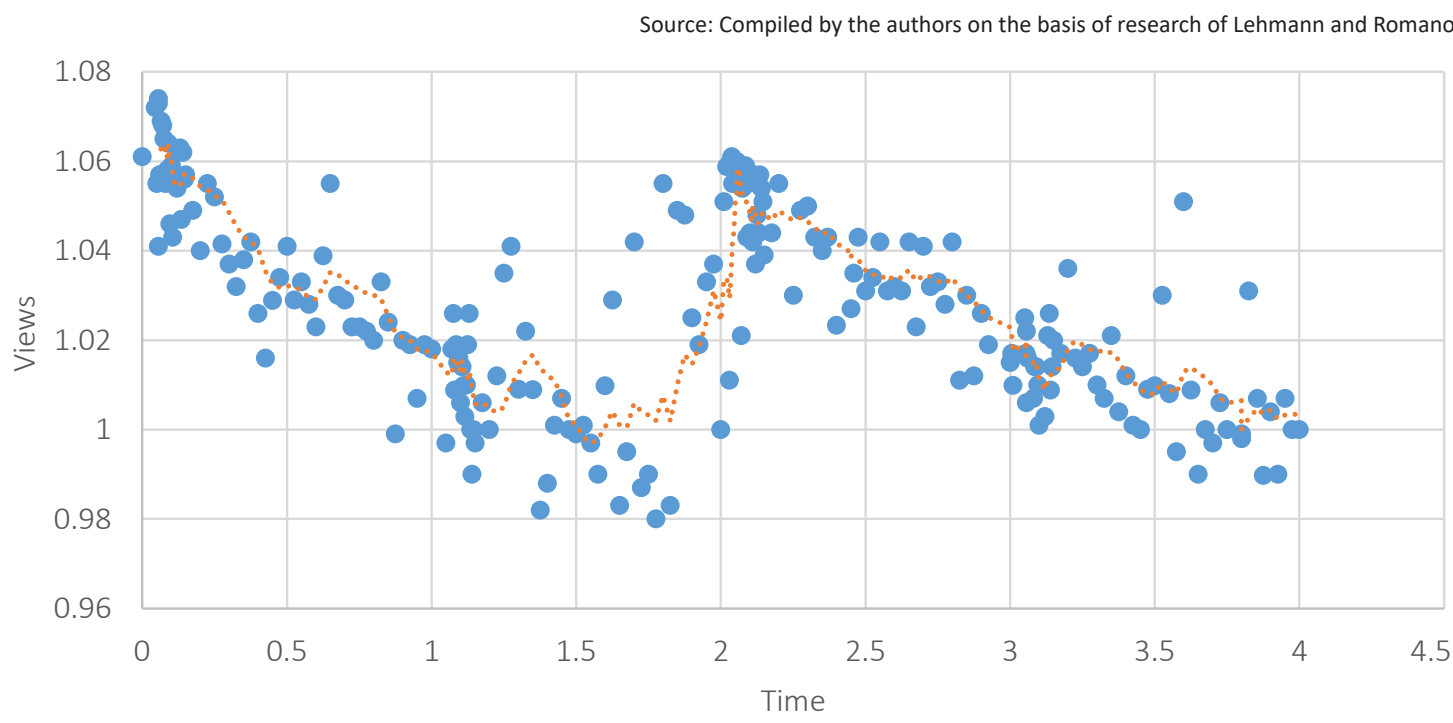

Figure 14. Approximation of time series of advertising reviews (dotted lines) in the system of successive advertising: In-Stream та TrueView Video Discovery (In-Display) (the OX axis is time, and on the OY axis - views) 
us expand the function (1) in the Fourier series the form of annotation review, which takes into that will permit to extend modeling of video ad- account manifestation of short-term current effect vertising messages, as an appropriate reaction in of the above signals.

Let us find the coefficients of the Fourier series:

$$
a_{0}=\frac{1}{1} \int_{0}^{1}\left(1.06^{1-x}\right) d x=\left.\left(-\frac{1}{\ln 1.06} 1.06^{1-x}\right)\right|_{0} ^{1}=\frac{0.6}{\ln 1.06}
$$

Marking the desired integral through I and using integration by parts, we find:

$$
\begin{aligned}
& a_{n}=2 I=\frac{1}{1 / 2} \int_{0}^{1}\left(1.06^{1-x}\right) \cdot \cos \left(\frac{n \pi x}{1 / 2}\right) d x=\left|\begin{array}{cc}
\left(1.06^{1-x}\right)=U, & -\left(1.06^{1-x}\right) \ln 1.06 d x=d U \\
\cos \left(\frac{n \pi x}{1 / 2}\right) d x=d V, \quad V=\frac{1}{2 n \pi} \sin \left(\frac{n \pi x}{1 / 2}\right)
\end{array}\right|= \\
& =2\left(\left(1.06^{1-x}\right) \cdot \frac{1}{2 n \pi} \sin \left(\frac{n \pi x}{1 / 2}\right) \mid \begin{array}{l}
1 \\
0
\end{array}+\frac{\ln 1.08}{2 n \pi} 6 \int_{0}^{1}\left(1.06^{1-x}\right) \sin (2 n \pi x) d x\right)= \\
& =\left|\begin{array}{c}
\left(1.06^{1-x}\right)=U, \quad-\left(1.06^{1-x}\right) \ln 1.06 d x=d U \\
\sin (2 n \pi x) d x=d V, \quad V=-\frac{1}{2 n \pi} \cos (2 n \pi x)
\end{array}\right|= \\
& =\frac{2 \ln 1.06}{2 n \pi}\left(\left(1.06^{1-x}\right)\left(-\frac{1}{2 n \pi} \cos (2 n \pi x)\right) \mid \begin{array}{l}
1 \\
0
\end{array}-\frac{\ln 1.06}{2 n \pi} \int_{0}^{1}\left(1.06^{1-x}\right) \cdot \cos (2 n \pi x) d x\right)= \\
& =\frac{2 \ln 1.06}{2 n \pi}\left(-\frac{1}{2 n \pi}(1-1.06)-\frac{\ln 1.06}{2 n \pi} \int_{0}^{1}\left(1.06^{1-x}\right) \cdot \cos (2 n \pi x) d x\right)=\frac{2 \ln 1.06}{2 n \pi}\left(-\frac{1}{2 n \pi}(1-1.06)-\frac{\ln 1.06}{2 n \pi} I\right) .
\end{aligned}
$$

Then, the coefficient $a_{n}$ is obtained in the form of:

$$
a_{n}=\frac{1}{1 / 2} \int_{0}^{1}\left(1.06^{1-x}\right) \cdot \cos \left(\frac{n \pi x}{1 / 2}\right) d x=\frac{2 \ln 1.06}{2 n \pi}\left(-\frac{1}{2 n \pi}(1-1.06)-\frac{\ln 1.06}{2 n \pi} \int_{0}^{1}\left(1.06^{1-x}\right) \cdot \cos (2 n \pi x) d x\right)
$$

Let us calculate the integral:

$$
\begin{aligned}
& \int_{0}^{1}\left(1.06^{1-x}\right) \cdot \cos \left(\frac{n \pi x}{1 / 2}\right) d x\left(0.5+\frac{2 \ln ^{2} 1.06}{(2 n \pi)^{2}}\right)=\frac{0.16 \ln ^{2} 1.06}{(2 n \pi)^{2}} \\
& a_{n}=\frac{0.16 \ln ^{2} 1.06}{(2 n \pi)^{2}} \cdot \frac{1}{0.5+\frac{2 \ln ^{2} 1.06}{(2 n \pi)^{2}}}
\end{aligned}
$$

or we have the final value of the coefficients:

$$
a_{n}=\frac{1.6 \ln ^{2} 1.06}{0.5(2 n \pi)^{2}+0.8 \ln ^{2} 1.06} .
$$


Similarly, we find the coefficient $b_{n}$ :

$$
\begin{aligned}
& b_{n}=2 I=\frac{1}{1 / 2} \int_{0}^{1}\left(1.06^{1-x}\right) \cdot \sin \left(\frac{n \pi x}{1 / 2}\right) d x=\left|\begin{array}{cc}
\left(1.06^{1-x}\right)=U, \quad-\left(1.06^{1-x}\right) \ln 1.06 d x=d U \\
\sin \left(\frac{n \pi x}{1 / 2}\right) d x=d V, \quad V=-\frac{1}{2 n \pi} \cos \left(\frac{n \pi x}{1 / 2}\right)
\end{array}\right|= \\
& =2\left(-\left(1.06^{1-x}\right) \cdot \frac{1}{2 n \pi} \cos \left(\frac{n \pi x}{1 / 2}\right)||_{0}^{1}-\frac{\ln 1.06}{2 n \pi} \int_{0}^{1}\left(1.06^{1-x}\right) \cos (2 n \pi x) d x\right)= \\
& =\left|\begin{array}{l}
\left(1.06^{1-x}\right)=U, \quad-\left(1.06^{1-x}\right) \ln 1.06 d x=d U \\
\cos (2 n \pi x) d x=d V, \quad V=\frac{1}{2 n \pi} \sin (2 n \pi x)
\end{array}\right|= \\
& =\frac{2 \ln 1.06}{2 n \pi}\left(\left(1.06^{1-x}\right)\left(-\frac{1}{2 n \pi} \cos (2 n \pi x)\right)\left|\begin{array}{ll}
1 \\
0
\end{array}\right| \frac{\ln 1.06}{2 n \pi} \int_{0}^{1}\left(1.06^{1-x}\right) \cdot \cos (2 n \pi x) d x\right)= \\
& =\frac{2 \ln 1.06}{2 n \pi}\left(-\frac{1}{2 n \pi}(1-1.06)-\frac{\ln 1.06}{2 n \pi} \int_{0}^{1}\left(1.06^{1-x}\right) \cdot \cos (2 n \pi x) d x\right)=\frac{2 \ln 1.06}{2 n \pi}\left(\frac{0.06}{2 n \pi}-\frac{\ln 1.06}{2 n \pi} I\right) .
\end{aligned}
$$

Thus, it follows from formula (5):

$$
b_{n}=2 I=\frac{1}{1 / 2} \int_{0}^{1}\left(1.06^{1-x}\right) \cdot \sin \left(\frac{n \pi x}{1 / 2}\right) d x=\frac{2 \ln 1.06}{2 n \pi}\left(\frac{0.06}{2 n \pi}-\frac{\ln 1.06}{2 n \pi} I\right),
$$

or

$$
I\left(2+\frac{2 \ln ^{2} 1.06}{(2 n \pi)^{2}}\right)=\frac{0.16 \ln 1.06}{(2 n \pi)^{2}} \Rightarrow I=\frac{0.16 \ln 1.06}{2(2 n \pi)^{2}+2 \ln ^{2} 1.06}
$$

From formula (6) we find the coefficients:

$$
b_{n}=\frac{0.16 \ln 1.08}{(2 n \pi)^{2}+\ln ^{2} 1.06} .
$$

Thus, we write down expanding the function in the Fourier series:

$$
f(x)=\frac{0.6}{\ln 1.06}+\sum_{n=1}^{\infty}\left(\left\{\frac{1.6 \ln ^{2} 1.06}{0.5(2 n \pi)^{2}+0.6 \ln ^{2} 1.06}\right\} \cos (2 n \pi x)+\left\{\frac{0.16 \ln 1.06}{(2 n \pi)^{2}+\ln ^{2} 1.06} \pi\right\} \cdot \sin (2 n \pi x)\right) .
$$

Let us consider 9 additive components of function (8). We have the form of graph presented in Figure 15 received in the program Wolfram Mathematics 11.

Thus, we can assume that function (8) is a continuous simulating function of advertising reviews with a synergistic effect of two types of advertising in YouTube in TrueView format: In-Stream and
TrueView Video Discovery (In-Display), which enables, depending on the advertising budget, to predict the advertising reviews in a particular situation when setting the parameters of the promotional video.

This will simulate the reaction from video advertising messages in the form of a feature of the feedback provided by the Fourier series. 
Source: Compiled by the authors on the basis of research.

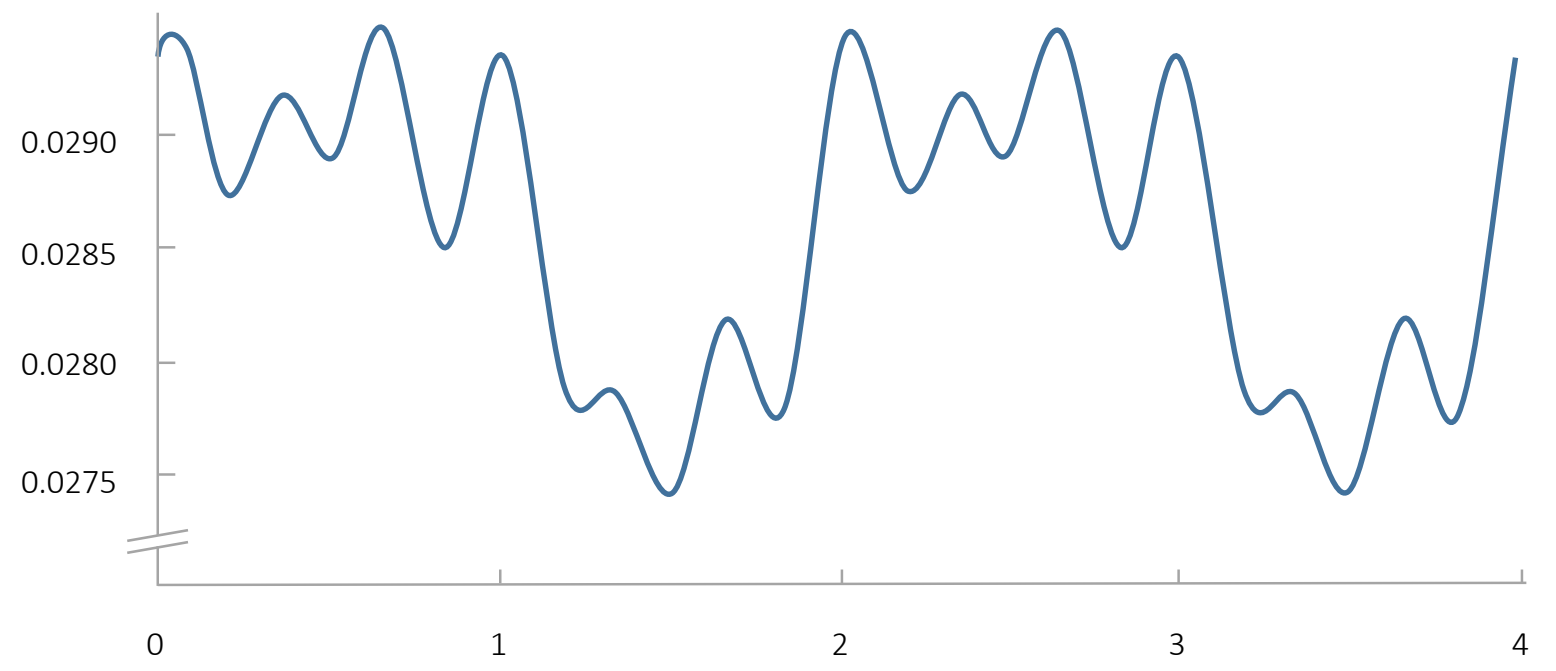

Figure 15. Visualization of 9 additive components of function (8)

\section{DISCUSSION AND CONCLUSION}

The rapid development of global information processes has significantly influenced the nature and features of the media market, which has actively harmonized with the advertising market over the last decade. Taking into account that the Internet rather than television as it was previously topped the list back in 2015 in terms of revenues from advertising, interest of the backbone providers to profit maximization has increased significantly. Ukraine, where the process of informatization has become extremely popular in the last five years, demonstrates this kind of global trends quite vividly, which confidently illustrates the number of users of the YouTube channel. It is forecast that the tendency of rapid spread of advertising video will be maintained over the next four to five years, however, there will be qualitative changes in the process of transition from the In-Stream to Out-Stream format. The author identifies the effects of using video advertising and highlights its benefits to YouTube (cost savings for image enhancement, brand support, sectoral perfection, unity of advertising platforms, etc.). It is determined that statistics of annotations (clicks, their number, closing of annotations, duration of advertising content viewing) may serve as indicative basis of the Internet advertising.

It has been found that during successive viewing of In-Stream and TrueView Video Discovery (In-Display) advertising account may be laid on the synergistic effect of advertising reviews, which will be amplified under the influence of increasing technology.

The modern process of identifying the economic effects of media advertising requires significant analytical efforts and, thus, additional calculations in view of the significant virtualization of production, marketing and financial variables. The novelty is that the use of Fourier series using the Moving Average Method allowed approximating the time series to exclude the influence of a random component, which opened additional opportunities for the video advertising messages simulation as the appropriate response to review of annotations. The foregoing fully takes into account manifestation of a short-term current effect of video advertising messages and, thus, ensures implementation of the business component of media advertising on the Internet.

Thus, the presented modeling of advertising responses with the help of Fourier series gives in practice an opportunity to model the prediction of the quality of responses to the proposed advertising hits, for which the peculiarities of their format are taken into account. 


\section{REFERENCES}

1. Dilley, J., Maggs, B., Parikh, J., Prokop, H., Sitaraman, R., \& Weihl, B. (2002). Globally distributed content delivery. IEEE Internet Computing, 6(5), 50-58. https://doi. org/10.1109/MIC.2002.1036038

2. Eelen, J., \& Seiler, R. (2015). Creative media use increases online sharing of your ad (but seems less effective for your brand). Advances in advertising research, VI, 291-308. http://dx.doi.org/10.1007/978-3658-10558-7_23

3. Florin, D., F., Vyas, S., Asad, A., Ion, S., Dilip, J., Aditya, G., Jibin, Z., \& Hui, Z. (2011). Understanding the impact of video quality on user engagement. Proceedings of the ACM SIGCOMM Conference on Applications, Technologies, Architectures, and Protocols for Computer Communication, 56(3), 362-373. http://dx.doi. org/10.1145/2018436.2018478

4. Fumi, A., Pepe, A., Scarabotti, L., \& Schiraldi, M. (2013). Fourier Analysis for Demand Forecasting in a Fashion Company. International Journal of Engineering Business Management, 5. https://doi. org/10.5772/56839

5. Giles, D. (2010). Psychology of the Media. London: Palgrave Macmillan.

6. Hilmes, M. (2011). Institutions: conflict and change. In The television history book (pp. 50-67) London: British Film Institute.

7. Hollander, M., Wolfe, D., \& Chicken, E. (1973). Nonparametric statistical methods (3rd ed.). New York: John Wiley and Sons. http://dx.doi. org/10.1002/9781119196037

8. Howkins, J. (2007). The creative economy. How people make money from ideas. London: Penguin Books.

9. Hutter, K. (2015). Unusual location and unexpected execution in advertising: A content analysis and test of effectiveness in ambient advertisements. Journal of Marketing Communications, 21(1), 33-47. https://doi.org/10.1080/13527 266.2014.970823

10. Krishnan, S. S., \& Sitaraman, R. K. (2014). Understanding the
Effectiveness of Video Ads: A

Measurement Study. Retrieved from https://www.akamai.com/fr/fr/ multimedia/documents/technicalpublication/understanding-the-effectiveness-of-video-ads-a-measurement-study-technical-publication. pdf

11. Küng, L. (2009). Strategic management in the Media. From Theory to practice. London: Sage Scannel, Paddy. Media and Communication. London: Sage.

12. Larson, R. C. (1987). Perspectives on queues: Social justice and the psychology of queueing. Operations Research, 35(6), 895-905. https://doi. org/10.1287/opre.35.6.895

13. Lehmann \& Romano, J. (2005). Testing statistical hypotheses. Springer Verlag.

14. Lin, C., \& Kim, T. (2016). Predicting user response to sponsored advertising on social media via the technology acceptance model. Computers in Human Behavior, 64, 710-718. https://doi.org/10.1016/j. chb.2016.07.027

15. Liu, X., Dobrian, F., Milner, H., Jiang, J., Sekar, V., Stoica, I., \& Zhang, H. (2012). A case for a coordinated internet video control plane. Proceedings of the ACM conference on Internet measurement conference, 359-370. Retrieved from https:// dl.acm.org/citation.cfm?id=2342431

16. Nelson, R. (2009). Analysing TV Fiction: How to Study Drama. In Tele - Visions an introduction to Studying Television (pp. 74-92). Glen Greeber. London: British Film Institute.

17. Nygren, E., Sitaraman, R. K., \& Sun, J. (2015). The Akamai Network: A platform for highperformance Internet applications. ACM SIGOPS Operating Systems Review, 44(3), 2-19. http://dx.doi. org/10.1145/1842733.1842736

18. Oktay, H., Taylor, B. J., \& Jensen, D. D. (2010). Causal discovery in social media using quasi-experimental designs. In Proceedings of the First Workshop on Social Media Analytics. In Proceedings of the ACM conference on Internet measurement conference, 1-9. https://doi. org/10.1145/1964858.1964859

19. Pierre, Guillet de Monthoux. (2013). The Art Firm: Aesthetic Management and Metaphysical Marketing. Kyiv: Companion Group.

20. Rauwers, F., Remmelswaal, P., Fransen, M., Dahlén, M., \& van Noort, G. (2018, August 31). The impact of creative media advertising on consumer responses: two field experiments. International Journal of Advertising: The Review of Marketing Communications. https:// www.tandfonline.com/doi/full/10.1 080/02650487.2018.1480167

21. Reijmersdal, E., Rozendaal, E., \& Buijzen, M. (2012). Effects of prominence, involvement, and persuasion knowledge on children's cognitive and affective responses to advergames. Journal of Interactive Marketing, 26(1), 33-42. https://doi. org/10.1016/j.intmar.2011.04.005

22. Scannell, P. (2008). Media and Communication (303 p.). Paddy Scannell. London: SAGE.

23. Shunmuga, S., \& Sitaraman, R. K. (2011). Video stream quality impacts viewer behavior: inferring causality using quasi-experimental designs. In Proceedings of the ACM conference on Internet measurement conference (pp. 211-224).

24. Shunmuga, S., \& Sitaraman, R. K. (2013). Understanding the Effectiveness of Video Ads: A Measurement Study. ACM Internet Measurement Conference (IMC). Barcelona, Spain. http://dx.doi. org/10.1145/2504730.2504748

25. Stádník, B., Raudeliuniene, J., \& Davidavičiené, V. (2016). Fourier Analysis for Stock Price Forecasting: Assumption and Evidence. Journal of Business Economics and Management, 17, 365-380. https:// doi.org/10.3846/16111699.2016.11 84180 